\title{
Investigating the Effect of Emergency Medicine Internship on Vocational Anxiety and Depression in Sixth Grade Students of the Medical Faculty
}

\author{
Abdullah Osman Koçak', Meryem Betos Koçak², Zeynep Çakır'1, Illker Akbaş', Burak Katipoğlu \\ 'Department of Emergency Medicine, Atatürk University School of Medicine, Erzurum, Turkey \\ ${ }^{2}$ Department of Family Medicine, Atatürk University School of Medicine, Erzurum, Turkey \\ ${ }^{3}$ Department of Emergency Medicine, University of Health Ankara Training and Research Hospital, Ankara, Turkey
}

Cite this article as: Koçak AO, Betos Koçak M, Çakır Z, Akbaş İ, Katipoğlu B. Investigating the Effect of Emergency Medicine Internship on Vocational Anxiety and Depression in Sixth Grade Students of the Medical Faculty. Eurasian J Emerg Med 2017; 16 : 153-6.

\begin{abstract}
Aim: The sixth grade of medical school is a true preparatory stage for the physicians. This places the physician candidates at stress before the emergency medicine (EM) internship and can lead to anxiety and depression. The present study is the first study to investigate depression, anxiety, and stress levels of sixth-grade medical students before and after the EM internship.
\end{abstract}

Materials and Methods: This is a prospective study,which is conducted on sixth-grade medical students. Anxiety, depression, and stress scores were assessed on the first and last day of the EM internship. The Beck depression and Beck anxiety scales and Depression Anxiety Stress Scale-42 (DASS-42) were used. Overall, 131 sixth-grade medical students who met the inclusion criteria were enrolled in the study.

Results: The mean Beck depression score was $10.15 \pm 6.11$ on the first day of internship and $6.37 \pm 4.79$ on the last day of internship. The difference was statistically significant $(p<0.05)$. The mean Beck anxiety score was $9.02 \pm 7.25$ on the first day of internship and $4.69 \pm 4.85$ on the last day of internship. The difference in Beck Anxiety score was statistically significant $(p<0.05)$. The mean DASS-42 scores were $23.91 \pm 14.35$ on the first day and $15.31 \pm 12.13$ on the last day. The difference was statistically significant $(p<0.05)$.

Conclusion: Sixth-grade medical students showed high scores on stress, anxiety, and depression scales before the EM internship, which is due to various reasons. However, as many causative factors disappear at the end of the internship and also as they experience the benefits of the EM internship, these scores drop on the last day of the internship.

Keywords: Anxiety, depression, intern doctors

\section{Introduction}

The medical faculty sixth grade studentship or the commonly used term internship and residency are the real preparation period for the medical profession. Students who have knowledge that it is more theoretical in the previous years of education to gain skills for both witnessing clinical applications in situ and examining patients in the presence of the responsibilities, making analysis and interpretation, and taking an active role in a number of interventional processes during the final year. Particularly, in the emergency medicine (EM) internship, students personally taking care of a patient for the first time, share the responsibility with EM assistants at the diagnosis and treatment stage of the disease. In addition, intern physicians, for the first time during EM internship, usually encounter the patient group that needs urgent and immediate intervention, such as those with cardiopulmonary arrest or multiple traumas, and are involved for the first time in this stressful environment.

Stress is defined as the negative psychological or physical consequences of any external stimulus created by an individual. Stress is the modest form of mood disorders. People with increased stress and 
failure in coping with it may develop anxiety and depression. Numerous factors from personal life to professional life may cause stress, depression, and anxiety (1). In addition, environmental factors and their changes are known to affect the level of stress in an individual (2).

Intern physicians are stressed even before starting the internship because of numerous responsibilities and changing environmental factors, thereby being victims of anxiety and depression. In this study, we aimed to measure reference levels of anxiety and depression of sixth grade students who experience intensive workload and stressful environment for the first time and to investigate the effect of 2-month period spent in the emergency department on these emotions.

\section{Materials and Methods}

This study was prospectively conducted on the medical faculty sixth grade students receiving EM internship between October 15, 2015, and June 01, 2016, in the emergency department of Atatürk University Medical Faculty. The students were subjected to Beck depression, Beck anxiety, and DASS-42 tests on the first and last days of EM internship, and anxiety, depression, and stress scores were determined.

The study was performed on a total of 138 students; 3 and 4 of the students(totally 7) were excluded from the study, respectively, due to "using antipsychotic drugs" and "not volunteering to participate in the survey," which were among the exclusion criteria. In total, 131 individuals took the first and last evaluation tests and completed the study.

Inclusion and exclusion criteria of the study are given in Table 1.

The participants who accepted to be enrolled in the study were taken to a private room in the emergency department and the survey forms were completed with a face-to-face interview.

Beck anxiety, Beck depression, and DASS-42 scales, which have been validated and translated to Turkish and were proven as reliable, were used to determine the depression and anxiety of the participants.

Beck anxiety scale is a self-assessment scale, used to determine the frequency of the anxiety symptoms that individuals experience. This scale provides a Likert-type (sum of ratings) measurement. There are 4 options in each of the 21 symptom categories. Each item is rated between 0 and 3 points. The severity of the anxiety experienced by the individual is derived from the total score of the scale.

Beck depression scale is a self-assessment scale, applied on both healthy and psychiatric patient groups. The objective of this scale is to determine the risk for depression and to measure the level and change in the severity of depressive symptoms. This form includes 21 self-assessment items and provides a 4-point Likert-type measurement. Each item is scored increasingly between 0 and 3 points, and the total score is obtained by the sum of these points. A high total score indicates high severity of depression.

DASS-42 was developed by Lovibond in 1995. The scale consists of 42 items with 14 belonging to depression (e.g., I couldn't seem to experience any positive feeling at all), 14 to anxiety (e.g., I was aware of dryness of my mouth), and 14 to stress (e.g., I found myself in situations
Table 1. Inclusion and exclusion criteria

\begin{tabular}{|c|c|}
\hline Inclusion criteria & Exclusion criteria \\
\hline $\begin{array}{l}\text { 1. Being volunteer to participate } \\
\text { in the study }\end{array}$ & $\begin{array}{l}\text { 1. Not volunteering to } \\
\text { participate in the study }\end{array}$ \\
\hline 2. Having no hearing impairment & 2. Having impaired hearing \\
\hline $\begin{array}{l}\text { 3. Being able to speak and read } \\
\text { in Turkish }\end{array}$ & $\begin{array}{l}\text { 3. Not being able to speak } \\
\text { and read in Turkish }\end{array}$ \\
\hline \multirow[t]{6}{*}{ 4. Having stable vital signs } & 4. Having no stable vital signs \\
\hline & $\begin{array}{l}\text { 5. Individuals with hormonal } \\
\text { dysfunction }\end{array}$ \\
\hline & $\begin{array}{l}\text { 6. Individuals using steroid, } \\
\text { anxiolytic, and sedative drugs }\end{array}$ \\
\hline & $\begin{array}{l}\text { 7. Individuals diagnosed with } \\
\text { severe anxiety disorder, active } \\
\text { psychosis, or dementia }\end{array}$ \\
\hline & $\begin{array}{l}\text { 8. Individuals with substance } \\
\text { abuse }\end{array}$ \\
\hline & $\begin{array}{l}\text { 9. Individuals with any chronic } \\
\text { disease }\end{array}$ \\
\hline
\end{tabular}

Table 2. Age distribution of the participants

\begin{tabular}{|l|c|}
\hline Age, years & Number of persons \\
\hline 22 & 2 \\
\hline 23 & 35 \\
\hline 24 & 39 \\
\hline 25 & 29 \\
\hline 26 & 14 \\
\hline 27 & 6 \\
\hline 28 & 3 \\
\hline 30 & 1 \\
\hline 34 & 1 \\
\hline 44 & 1 \\
\hline
\end{tabular}

that made me so anxious) dimensions. This scale is designated for the measurement of depression, anxiety, and stress symptoms that present from the time it is applied, including the last week (3). Written informed consent was obtained from participants who participated in this study.

\section{Statistical analysis}

Data obtained were evaluated using the Statistical Package for Social Sciences version 20 (IBM SPSS Statistics; Armonk, NY, USA) package software. A paired-sample t test was used for comparing the variables showing normal distribution. All data were expressed as mean \pm standard deviation, and $p<0.05$ values were considered statistically significant.

\section{Results}

A total of 131 sixth grade interns in the Atatürk University Medical Faculty voluntarily participated in the study. Of the participants, 77 (58.8\%) were males and $54(41.2 \%)$ were females. The mean age was 24.64 \pm 2.34 years ( $\min -\max , 22-44$ ), and the median age was 24 years. The age distribution of the participants is shown in Table 2. 
Table 3. Overall scores obtained from the stress, anxiety, and depression tests applied on the first and last days

\begin{tabular}{|l|c|c|c|}
\hline & $\begin{array}{c}\text { Beck } \\
\text { depression, } \\
\text { mean } \pm \\
\text { standard } \\
\text { deviation }\end{array}$ & $\begin{array}{c}\text { Beck } \\
\text { anxiety, } \\
\text { mean } \pm \\
\text { standard } \\
\text { deviation }\end{array}$ & $\begin{array}{c}\text { DASS-42, } \\
\text { mean } \pm \\
\text { standard } \\
\text { deviation }\end{array}$ \\
\hline $\begin{array}{l}\text { Mean scores } \\
\text { of the first day }\end{array}$ & $10.15 \pm 6.11$ & $9.06 \pm 7.25$ & $23.91 \pm 14.35$ \\
\hline $\begin{array}{l}\text { Mean scores } \\
\text { of the last day }\end{array}$ & $6.37 \pm 4.79$ & $4.69 \pm 4.85$ & $15.31 \pm 12.13$ \\
\hline
\end{tabular}

The mean value of Beck depression scale on the first day was $10.15 \pm 6.11$ (min-max, 1-37) and median value was 9. The mean value of Beck depression scale on the last day was $6.37 \pm 4.79$ (min, 0; max, 23) and the median value was 5 . This decrease in Beck depression scale mean values between the first and last day was statistically significant $(p<0.05)$.

The mean value of Beck anxiety scale of the participants on the first day was $9.02 \pm 7.25$ (min-max, 0-33) and the median value was 7. The mean value of Beck anxiety scale on the last day was $4.69 \pm 4.85$ (minmax, 0-22) and the median value was 3. This decrease in Beck anxiety scale mean values between the first and last day was statistically significant $(p<0.05)$.

The mean value of DASS-42 of the participants on the first day was $23.91 \pm 14.35$ (min-max, 0-66) and the median value was 22. The mean value of DASS-42 scale on the last day was $15.31 \pm 12.13$ (minmax, 0-61) and the median value was 12 . The difference was statistically significant $(p<0.05)$.

We designed the tests to evaluate the diseases that are frequently encountered in emergency department; the mean score on the first day was $24.37 \pm 11.15$ ( $\min -\max , 3-54)$ and the median score was 23 , while the mean value on the last day was $13.31 \pm 8.34$ (min-max, $0-43$ ) with a median score of 12 , and the difference was statistically significant $(p<0.05)$. When the scores obtained from the tests were compared according to gender, no statistically significant differences were found between the two sexes ( $p>0.05$ ).

The first and last day points obtained from the tests applied on the participants are summarized in Table 3.

\section{Discussion}

To our knowledge, this study is the first to investigate depression, anxiety, and stress levels of the medical faculty sixth grade students before and after EM internship. When the levels of these three factors were compared between the first and last days of the emergency department internship, the first day values were found to be higher than those of the last day, and the difference was statistically significant. We think that this may be because interns become stressed anticipating that a difficult environment they never knew and were unfamiliar is waiting them, and after 2 months spent in EM, they comprehend that it was not something to be feared owing to the experience they have gained. We have discussed the reasons for stress, anxiety, and depression before starting EM internship.

\section{Changing environment}

Today, stress, anxiety, and depression are recognized as general emotional problems by many researchers. People often experience these three moods in daily life. Stress is the mildest and most common of these moods. It is described as the negative psychological or physical consequences of any external stimulus created by the individual. Evidently, although there are many factors that can cause stress in every person's daily life, being under the influence of stress varies from person to person. Numerous factors in daily life, such as natural disasters, familial problems, economic concerns, professional troubles, problems experienced in traffic, and environmental factors may be a source of depression, anxiety, or stress (1). In our study, changing environment and being involved in a new environment and a more challenging professional tempo than other internships might have caused stress, anxiety, and depression in our participants.

\section{Working in the field of health}

Various studies have shown that health care workers are under severe stress compared to other occupational groups (4). In health care organizations, depression symptoms may develop when appropriate coping mechanisms are not applied for stress resulting from daily events and the profession $(5,6)$. Medical faculty sixth grade is the preparation period for the medicine profession. Moreover, the interns take the responsibility of a patient for the first time during EM internship. The interns who consider themselves more responsible for a patient for the first time might be more stressful, anxious, and depressive.

\section{Violence in health}

Studies have shown that violence occurs most commonly in the health care field compared to the other occupational areas. It has been reported that violence toward health care workers worldwide and in Turkey is a serious professional problem that needs to be emphasized (7). Violence incidents lead to long-lasting adverse effects on health care professionals, such as enervation, loss of labor, reduction in job satisfaction, anxiety, stress disorder, feeling of insecurity, depression, alcohol abuse, smoking, suicide, and deterioration in interpersonal relations (8-13). It is known that exposure to violence is most often experienced in emergency services (14).

Increasing violent events towards the health care professionals that are most commonly experienced in emergency department might be a factor of anxiety and stress before the internship.

\section{The challenges of working in emergency services}

Emergency departments are an extremely stressful area of work by nature. Emergency physicians must make and apply quick and correct decisions. Therefore, EM is associated with specific problems and functioning compared to the other departments. EM clinics are and will continue to be one of the most exhausting units of hospitals in the conditions of our country. Emergency department is an area where many and different diseases are simultaneously encountered, and patients present with different complaints then previous patients (15). Even minor mistakes in emergency departments may cause severe mortality and morbidity of the patients. However, the crowded environment of emergency departments always increases the probability of mistakes. Working conditions, overtime, and workload of physicians in emergency departments is another factor increasing 
stress and tension in the environment. Furthermore, emergency departments provide 24-hour service therefore the emergency department staff continue to work on weekends and long public holidays. These reasons might be important factors affecting the levels of stress, anxiety, and depression in these participants who are part of emergency health care team during the 2-month internship period. In our study, no statistically significant difference was found between the two sexes in the scores obtained from stress, anxiety, and depression on the first and last days of the internship. In general, women are more likely to be depressed (16). The reason for no significant difference found between the genders might be related to the source of stress arising from professional life rather than private life. The two sexes receiving educations in similar conditions during 6 years and having common concerns about the emergency department might have caused this result. Similar publications in the literature that have been conducted on populations similar to ours, supporting our hypothesis $(1,17)$.

\section{Study limitations}

Our work is single-centered study. Our study was relatively small number of participants and scope of a certain period.

\section{Conclusion}

Individuals may develop anxiety and depression due to many different factors, including changing social environment, physical environment, emotional state and change of mental-biological functions. Medical faculty sixth grade students get high scores on the stress, anxiety, and depression scales before starting to EM internship due to many reasons, but the last day scores are decreased as a result of elimination of many factors that we think as a reason of this situation and by experiencing the good aspects of working in emergency departments.

Ethics Committee Approval: Ethics committee approval was received for this study from the ethics committee of Atatürk University School of Medicine.

Informed Consent: Written informed consent was obtained from participants who participated in this study.

Peer-review: Externally peer-reviewed.

Conflict of Interest: No conflict of interest was declared by the authors.

Financial Disclosure: The authors declared that this study has received no financial support.

\section{References}

1. Üstün A, Bayar A. An investigation of university students' depression, anxiety and stress levels related to the different variables. Journal of Research in Education and Teaching 2015 4: 36.

2. Kapcı EG. Bullying type and severity among elementary school students and its relationship with depression, anxiety and self esteem Ankara University. Journal of Faculty of Educational Sciences 2004; 37: 1-13.

3. Çevik A, Volkan VD. Psychodynamic etiology of depression. Depression Monograph Series 3. 1993.p.109-22.

4. Heim E. Job stressors and coping in health professions. Psychother Psychosom 1991; 55: 90-9. [CrossRef]

5. Karagozoglu S, Bingol N. Sleep quality and job satisfaction of Turkish nurses. Nurs Outlook 2008; 56: 298-307. [CrossRef]

6. Bjørk IT, Samdal GB, Hansen BS, Tørstad S, Hamilton GA. Job satisfaction in a Norwegian population of nurses: a questionnaire survey. Int J Nurs Stud 2007; 44: 747-57.

7. Büyükbayram, A. Okçay, H. The Socio-Cultural Factors That Affect Violence in Health Care Personnel. J Psy Nurs 2013; 4: 46-53. [CrossRef]

8. Ünsal Atan Ş, Dönmez S. Workplace Vıolence Agaınst Nurses. J For Med 2011; 25: 71-80.

9. Ayranci U, Yenilmez C, Balci Y, Kaptanoglu C. Identification of violence in Turkish health care settings. J Interpers Violence 2006; 21: 276-96. [CrossRef]

10. Franz S, Zeh A, Schablon A, Kuhnert S, Nienhaus A. Aggression and violence against health care workers in Germany-a cross sectional retrospective survey. BMC Health Serv Res 2010; 10: 51. [CrossRef]

11. Estryn-Behar M, van der Heijden B, Camerino D, Fry C, Le Nezet O, Conway PM, et al. Violence risks in nursing-results from the European 'NEXT' Study. Occup Med (Lond) 2008; 58: 107-14. [CrossRef]

12. Dursun S. The Effect of Workplace Violence on Employees' Level Burnout: An Application on Health Sector. Journal of Labour Relation 2012; 3: 105-5.

13. PInar T, PInar G. Healthcare Workers and Workplace Violence TAF Prev Med Bull 2012; 12: 315-26.

14. Illhan MN, Özkan S, Kurtcebe ZÖ, Aksakal FN. Exposure to Violence and Related Factors Among Research Asistans and Intern Doctors in Gazi University Hospital. Social Society Bullettin 2009; 28: 15-23.

15. Aydın T, Aydın ŞA, Köksal Ö, Özdemir F, Kulaç S, Bulut M. Evaluation of Features of Patients Attending the Emergency Department of Uludag University Medicine Faculty Hospital and Emergency Department Practices 2010. Eurasian J Emerg Med 2010; 9: 163-8.

16. Blazer DG. Mood disorders: Epidemiology. In: Sadock BJ, Sadock VA (eds). Comprehensive Textbook of Psychiatry. Vo1 I. 7th ed. Philadelphia: Lippincott Williams \& Wilkins, 1999: 1298-308.

17. Üskül B, Selvi A, Melikoğlu A, Varol N, Türker H. Relationships between anxiety and depression levels and socio-demographical factors and diagnoses of the patients admitted in the department of chest diseases. Turkiye Klinikleri Arch Lung 2006; 7: 11-5. 